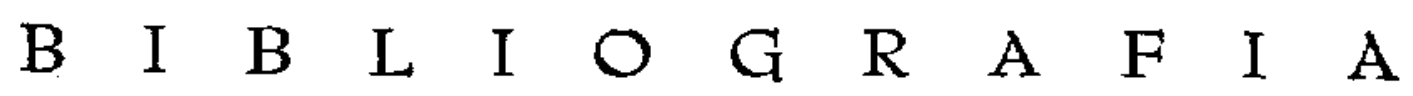

FELIPE COSSIO DEL POMAR: Arte del Perú Precolombino. Ed. Fondo de Cultura Económica. México, 1949. 214 págs. con ilustraciones.

La obra se divide en xII capítulos, de los cuales el primero estudia los conceptos fundamentales que sustentan la diferencia entre arqueología e historia del arte, y los demás tratan de la producción artística de los diversos pueblos que en conjunto integran el arte indígena peruano, desde la legendaria cultura del Titicaca (Tiazenrako), hasta la del soberbio imperio inca. A veces en exceso esquemática (al periodo pre-incaico el autor le dedica sólo un par de líneas), la animada exposición no deja ni un momento de apoyarse en las opiniones de arqueólogos y filósofos, en un esfuerzo por elaborar una teoria consistente que explique el arte americano, con especialidad el peruano, y que al mismo tiempo sirva de base para interpretarlo y para așimilarlo a la historia general del arte.

En su esfuerzo por distinguir entre historia del arte $y$ arqueología, el autor llega a decir, en la pág. 4: "A la arqueología le corresponde estudiar las representaciones plásticas en sus fuentes primitivas: aspecto, material, relación, analogía y diferencia con otras civilizaciones." $Y$ un poco más adelante: "A su vez el historiador del arte reclama una función menos precisa y más trascendental : el estudio esencial en un acatamiento integral del proceso evolutivo de la cultura del hombre" (en ambas citas subrayamos mosotros). A juicio muestro, esas ideas requieren, por lo menos, un comentario, si no es que un examen cuidadoso. Hemos crédo que el arqueólogo es precisamente el científico que estudia desde el punto de vista histórico los restos (no necesariamente las representaciones plásticas), que nos han dejado las culturas prehistóricas, con el fin de aclarar el horizonte vital; es decir, su función se asimila mucho más a la actividad científica que a la artística, ya que opera con su material a Ia manera del historiador con los documentos, de suerte que sólo tiene que ver con la "forma plástica" en cuanto ella puede servirle para aclarar el pasado: es ciencia auxiliar de la historia, en una palabra. En cambio, el historiador del arte tiene que ver, éste sí, ante todo con la "forma plástica", a fin de interpretar y valorar las manifestaciones artisticas, que después unirá en un todo armónico, pues no podemos concebir una historia del arte que no enlace la secuencia de los estilos, a la vez que los distinga y sitúe, en cuanto ello es posible, en el tiempo. Ciencia frente a arte, verdad frente a belleza, valores que debemos tener cuidado de no confundir. Por 
supuesto, estamos de acuerdo con el autor en que "el investigador arqueológico tiene forzosamente que reducir su actividad y su ciencia al conocimiento concreto de ese trozo de la realidad en sí mismo...", y en que "el historiador del arte tiene que basarse necesariamente, en el estudio de los documentos descubiertos por el arqueólogo".

En alguna ocasión, incurre en alguna contradicción esencial. Afirfina, con muchísima razón, que es imposible estudiar cualquier arte americano siguiendo el sentido cronológico occidental,1 lo que implica poner en su contexto único a la obra de arte; o lo que es lo mismo, a presentar los fundamentos ideológicos y religiosos que sustentan el mundo espiritual del indígena y que son, por lo tanto, el fondo imprescindible de su abra artística; pero, inconsecuente con su propia doctrina, no nos da un solo cuadro histórico, no nos hace una exposición, por breve que fuera, del mundo espiritual del indígena, que sería, en todo caso, la base para comprender sus manifestaciones artísticas.

La información es abundante, casi siempre de primera mano, y se apoya en los trabajos de muy distinguidos investigadores: Seler, Joyce, Uhle, Tello. Tal vez pudiera haberse hecho una pintura más elocuente del maravilloso arte peruano si se hubiera atendido más a la descripción y comentario de las obras mismas de arte, aunque ello fuera en detrimento de la brillantez de las imágenes o de la rotundez de las afirmaciones. En efecto, en ciertas ocasiones se siente que el libro no responde cabalmente a su título, mientras que en otras parece que ai autor se le va la mano al seguir ciertas pistas; ${ }^{2}$ asi, la interpretación de las formas y de los estilos, la situación estilística de los objetos apenas apunta a lo arcaico y a lo clásico, haciendo una tímida agrupación de estilos y culturas. Todo esto carecería de importancia si el Iector estuviera familiarizado con los restos prehispánicos de la cuitura peruana; tal vez en ese descuido esté la causa de los defectos del libro, pues el texto se formó del de las conferencias que el antor sustentó en Lima. El mundo del arte americano, de por sí extraño dados sus fundamentos particularísimos, no puede presentarse en igual forma ante públicos que tienen un conocimiento muy diverso de la antigua cultura peruana.

Sorprende encontrar un notable parecido entre la cerámica animalista Mochik y la elaborada por nuestros pueblos del occidente de México. Y es de notarse la preferencia común del artista indigena por la representación de ciertos animales: águila, serpiente, etc., así como el uso insistente, también común a culturas tan geográficamente distantes coino lo son la peruana y la mexicana, de ciertos colores:

1 Worringer, en su ya clásico libro La esencia del estilo gótico ha presiddo esta idea de la autonomía artística, y Salvador Tascano, en su Arte Precolambino de México y de la América Central, la adoptó utilizándola para su estudio. No se trata, pues, de algo completamente nuevo.

2 Véase, por ejemplo, su interpretación de la greca, que llama, con toda propiedad aunque apartándose un tanto de la tradición, "ortogonal", y que llega a ser, para él, "el omnipotente signo escalonado, suma de ángulos ortogonales, expresión de la perfeccón basada $n$ el ángulo recto..." "... representación del orden cósmico, síntesis del hieratismo deológico de una cultura labrada en metal, en piedra, en madera..." "... figura representativa de la trantuilidad y el reposo al que aspiran los pueblos que han trabajado mucho o que han sufrido mucho..." Etc. 
rojo y amarillo, posibles fuentes para la elaboración de una psicología artística indigena.

Indudablemente, es un gran acierto del autor el estudiar el arte peruano por culturas, pues sabemos que la civilización precolombina de América se desarrolló por medio de grupos aislados, en épocas diferentes que cubren una gran extensión de tiempo, por eso también resulta acertado su planteamiento de la relación de espacio-tiempo de todas estas culturas, hasta su fusión en el imperio inca, uno de los más pujantes de América.

Apenas menoscaba el mérito informativo del libro algún errot de poca monta. El autor habla de la "pictografía tolteca", cuando sin duda se refiere a la azteca; menciona a "la diosa Texcatlipoca", mas en verdad se trata del dios Tezcatlipoca, de gran historial en las culturas del Valle de México; habla de "las cabezas que adornan los templos toltecas" pero con seguridad se refiere a los edificios de Teotihuacán.

Desgraciadamente algunas ilustraciones no son reproducciones tomadas directamente del original, sino de copias hechas por artistas peruanos, que en algunos casos (véase la lámina 5) no han sido muy afortunados en su interpretación.

Finalmente, conviene mencionar algunas erratas del libro que los editores pueden tomar en cuenta para una futura edición:

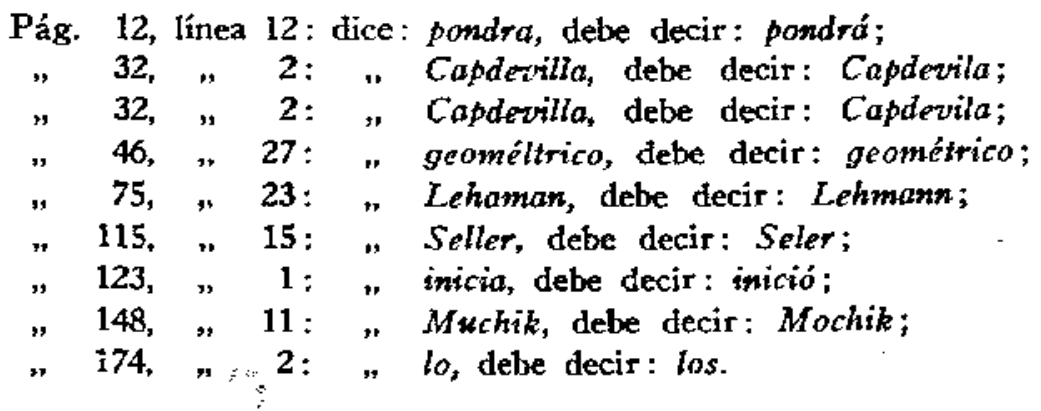

Carlos Villegas.

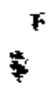

AGUSTIN VILLAGRA CALETI : $B O-$ nampak. Instituto Nacional de Antropología e Historia. México, 1949.

Esta monografia, pulcramente impresa, es el fruto de dos temporadas de trabajo (1947 y 1948) en la última ciudad mava descubierta hasta hoy. Contiene una breve pero jugosa nota preliminar de Salvador Toscano y un amplio estudio del autor. Las ilutstraciones a color y en negro completan el trabajo.

Según Toscano, se puede atribuir la erección de Bonampak al siglo viri, Edad de Oro de los mayas, pues la estela $\mathrm{I}$ de esa ciudad ostenta la fecha 785 . Los murales, que podemos disfrutar gracias a la habilidad técnica de Villagra, recuerdan un tno mento histórico de la vida de la ciudad, pues ciertos personajes se presentan con in- 
sistencia nada casual; de paso, nos ilustran sobre instrumentos y atavios, mismos que nos eran punto menos que desconocidos. Pero sobre todo, y tal vez en esto radique su importancia fundamental, nos permiten conocer de cerca el arte pictórico de la gran época maya. La técnica empleada, de acuerdo con el autor, es la siguiente: se trazaba el dibujo con rojo indio sobre el aplanado blanco, luego se pintaba el fondo, se llenaban después los huecos con los colores respectivos, y por último se sileteaban las figuras con negro. Los colores empleados con más frecuencia son : negro, blanco, amarillo ocre, rojo indio, rojo naranja, siena quemado, verde esmeralda, verde seco, etc.

Las ilustraciones, obra del pincel de Villagra, sin duda son lo más notable de la monografia. El autor tuvo que recurrir en alguna ocasión a reconstruir trozos del fresco destruidos por la humedad, auxiliándose con el contexto; cuando éste no suministró datos suficientes, se tuvo el acierto de dejar el hueco original.

\section{Carlos Villeggas.}

\section{JUAN ALMELA MELIA: Manual de reparación y conservación de libros, es- tampas y manuscritos. México, 1949.}

Esta utilísima publicación fué realizada por el benemérito Instituto Panamericano de Geografia e Historia, entre los "Manuales de técnica de la investigación de la Historia y ciencias afines", que organiza la Comisión de Historia. No menos digno de encomio y así lo dice el señor Almela, es el Instituto Nacional de Antropologia e Historia que lo acogió y le proporcionó un modesto taller en que lleva siete años de continua labor, salvando libros manuscritos y cuanto se le lleva y, sobre todo difundiendo sus enseñanzas. Con esa emocionante modestia, característica de todo hombre que vale nos dice: "En el presente Manual no descubrimos nada. Nuestro propósito es difundir el conocimiento..." Qué raro es encontrar a un maestro como éste que ensefra todo lo que sabe en un oficio que puede ser productivo.

Muchos de nosotros conocimos a un profesor de grabado en lámina en la vetusta Academia de San Carlos que consideraba como un secreto de propiedad personal suya i la fórmula de los ácidos que atacan al cobre! En vez de dar la receta a sus alumnos prefería gastar de su peculio y llevar el mordente en frascos a su clase que luego recogía con todo cuidado.

No voy a referirme a las cualidades técnicas del libro de Maese Almela. Quienquiera que entienda un poco de libros y sus concomitantes se daráa cuenta de que es excelente. Lo es por su claridad, por su sencillez, por su ninguna pedantería de términos rebuscados o tono doctoral y por la eficiencia que revela.

Quiero elogiar la humanidad que aparece en este tratado. Maese Almela, un buen viejo bonachón y simpático, conversa con nosotros acerca de su oficio como si fuésemos discípulos suyos, en su pequeño taller medieval del arcaico museo de la calle de la Moneda. i Qué bueno que no tenga un laboratorio moderno, lleno de máquinas y reflectores, $y$ ayudantes como enfermeras o médicos 1 
Al trabajar Maese Almela personaliza a sus víctimas: "Hemos expuesto lo que llamamos el desarrollo normal, o sea cuando la suciedad y las manchas han cumplido s* obligación de desaparecer sin resistencia. Desgraciadamente existen manchas recalcitrantes a quienes el trato o tratamiento normal parece tenerles sin cuidado y persisten en 'sus trece'. ¿De dónde había venido esta endiablada mancha ?" "Se trata - perdónese la humorada- de "pillar descuidada' a la tinta de la estampación".

Y claro que perdonamos no sólo ésta sino todas las deliciosas humoradas del libro. $\mathbf{Y}$ conclúímos esta cordial resefia bibliográfica preguntándonos: ¿ no es así como fueron escritos los tratados clásicos para - digamos asi-, dar recetas al artista? ¿ Desde Leonardo, Cenino Cenini, Benvenuto, hasta los nuestros, Pacheco, López de Arenas, Carducho, Jusepe Martínez? (Perdonémosle sus polendas al señor Palomino). Indudablemente, Maese Almela es el tratadista clásico, de 1949, acerca de la Reparación de libros, estampas y manuscritos.

M. T.

LEOPOLDO I. ORENDAIN : Los pretendidos Murillos del Museo de Guadalajara. Guadalajara, Jal. México, 1949.

El propósito de este folleto, verdaderamente encomiable, es destruir la leyenda forjada en el siglo xIx, como tantas otras, que atribuye a Murillo la paternidad de una serie de grandes telas que custodia el Museo de Guadalajara. Abundo en la opinión del señor Orendain (la del Padre Palacio no puede ser tomada en cuenta), que niega que tales cuadros sean de Murillo. Pero no así cuando pasa al extremo optresto de considerarlos como de cualquier pintor colonial del siglo xvII. Es indudable, que si no son de Murillo, sí son murillescos de buena época, siglo xvit, pintados en Nueva España para el convento de Guadalajara, con las medidas exactas de su claustro y como lo demuestra el detalle iconográfico de los petates que observa el señor Orendain, y que yo le hice nofar a Angulo. Mi hipótesis es que se deben a un discipulo o imitador de Murillo - ilonso Cano quiere el crítico espaniol-, que anduvo por estas tierras en el siglo. décimoséptimo. Basta estudiar barba y cabello en los retratos que aparecen para convencernos de que son del xir.

En cuanto a semejanzas con los pintores coloniales del siglo xvin son evidentes, y se deben a dos causas: los artífices dieciochescos procuran modificar, acaramelándolos a su gusto, todos los cuadros que caen bajo su pincel indocto, so pretexto de restaurarlos. El segundo factor, más profundo, radica en que toda la pintura mexicana de 1700 está enormemente influenciada por Murillo; no el vigoroso costumbrista, ni el creador de intensos temas religiosos, sino el fabricante de infinidad de santos y Purísimas dulzones que imundaron España y América. Pero estos cuadros revelan todavía gran dignidad, así en su sólida construcción como en su colorido sobrio y sombrío. Decir que pueden ser de "cualquier buen cabrerista" es dar una opinión a la ligera. 
E1 señor Orendain nos ofrece, pues, un estimable trabajo, discutiendo con sana crítica el problema histórico y dejando abierto el campo para investigaciones posteriores, acerca del autor de los cuadros. Las fotografias que reproduce serán para eso muy útiles.

M. T.

\begin{abstract}
ADOLFO LUIS RIBERA $\times$ HECTOR SCHENONE: El Arte de la Imaginteria en al Ría de la Plala. Universidad de Buenos Aires, 1948.
\end{abstract}

Profusamente ilustrado con magníficos fotograbados y nítidamente impreso, aparece este libro que, como dice el P. Guillermo Furlong en su Prólogo, "es único en su género, por su originalidad, por su vastedad, por su intensidad y por su tonalidad." En efecto, abarca la historia del desarrollo de ese arte tan español, como es la escultura religiosa, en las provincias del antiguo Virreinato del Rio de la Plata.

Después de reseñar los aportes extranjeros de España, Italia y aun de algunos puntos de la propia América del Sur, y de mencionar los nombres de algunos escultores que de la Madre Patria vinieron, entran de lleno los autores en el desarrollo de su sugestivo tema.

En la primera sección de su obra disertan extensamente acerca de la imagineria norteña, la imagineria en las misiones guaraniticas y la imaginería en Buenos Aires.

Los Tipos de Imógenes y su técnica, se estudian en la segunda sección, a saber: las de "talla completa", las "de vestir", y las "de tela encolada"; y remata la obra una nutrida relación de los Santos y su representación, que recuerda el Pictor Christianus, de Iterián de Ayala, y en el cual, por orden alfabético, se describen los santos representados en la escultura platense, con una ligera noticia biográfica, sus atributos, e indicación de algunos lugares en donde se encuentran sus imágenes.

Siguen numerosas notas $y$ abundante bibliografía para terminar con las excelentes ilustraciones a que hemos aludido.

Los amplios datos históricos que contiene esta obra, con una que otra alusión a nuestro país, y la atinada crítica artística que la anima constituyen un conjunto de verdadera importancia. $Y$ es motivo de la mayor complacencia para nuestro Instituto, el hecho de que en él se inspiró la Universidad de Busenos Aires nara crear su Instituto de Arte Americano e Investigaciones Estéticas, que dirige el diligente don Mario J. Buschiazzo.

Por cierto que el forro y la portada, del libro que reseñamos, se exornan con el grabado en madera de la Virgen Conquistadora, que, según Pérez Salazar, ejecutó un tal Zúñiga en Puebla, por los años de 1719.

M. R. de T. 
FELIX COLUCCIO: Folklore de las Américas. Primera Antología. Con Prólogo de Augusto Raúl Cortazar. Librería "El Ateneo", Buenos Aires, 1949. 456 págs.

Es la segunda obra de este joven investigador que llega a nuestras manos, y del mismo modo que su Diccionario Folklórico Argentino, mantiene el mismo vigor, entusiasmo y certera visión de este Folklore de las Américas. Es, en realidad, un alarde de condensación de las manifestaciones más salientes de la cultura tradicional americana, en forma panorámica y observada desde el extremo sur del continente. En esta anfología aparecen, por orden albabético, representados los veintidos países de América, desde el Canadá hacia el Sur, y lo mismo la música, el canto y la danza; mitos creencias y superticiones; refraneros, adivinanzas, provincialismos; juegos de salón, juegos infantiles, deportes regionales y tópicos locales como la doma de potros en Argentina; la pulperia unuguaya y aún la yerba mate en todos sus aspectos.

V. T. $\mathrm{M}$.

F. S. C. NORTHROP : La Filosofia y el Arte Contemporíneo. Instituto Mexicano Norteamericano de Relaciones Culturales. México, 1949.

Un folleto bien presentado que recoge la conferencia que dió el doctor Filmer S. C. Northrop, profesor de filosofia de la Universidad de Yale, en el Palacio de Bellas Artes, de México, el mes de marzo de 1949, bajo los auspicios del Instituto Mexicano Norteamericano de Relaciones Culturales. Es ya casi innecesario decir que el doctor Northrop es el autor del famoso estudio filosófico titulado El Encuentro del Oriente y Occidente, sin cuyo conocimiento es más dificil comprender los alcances de la conferencia a que vamos a referimos: La Filosofía y el Arte Contemporáneo.

La viveza el entusiasmo que el Dr. Northrop pone en sus exposiciones de viva voz, sus enormes conocimientos y la claridad con que expone sus ideas, to hacen un conferenciante muy personal y de excepción. No sólo en la conferencia aludida, sino en la serie que aguel mes y año sustentó en la Facultad de Filosofía y Letras de la Universidad Nacional, los asistentes pudieron comprobar lo anterior, así como la natural sencillez de su personalidad, su buena fe y sus altas miras.

Veamos la tesis sustentada por el Dr. Northrop en aquella ocasión en que puso en contacto dos expresiones de la cultura : la filosofía y el arte contemporáneo, diciendo a manera de introducción: "... sin el arte, probablemente no es posible que haya libertad ni paz en el mundo."

En ese inicial pensamiento se encuentra la liga con la idea central del doctor Northrop desde su libro The Meeting of East and West, que lleva el siguiente subtitulo explicativo: "an inquiry concerning world understanding"; encontrar la forma de 
un posible entendimiento mundial es la finalidad del autor y en ello el arte tiene su función. Pero antes de decirnos cual, el doctor Northrop explicó que el arte tiene dos funciones: una primera es la expresión de materiales estéticos que no ocultan, ni transmiten, porque no contienen, ninguna teoria, es el hecho puro por su propio valor; una segunda función del arte es aquélla en que usando los materiales estéticos, el hecho puro, trasmite por inferencia un hecho, especificado por medio de una doctrina. El mejor ejemplo de la primera función del arte, el arte puro, lo ha eficontrado el doctor Northrop en nuestro hemisferio en el caso de la pintura de Georgia O'Keeffe, a quien llama "uno de los más grandes y originales artistas de mundo contemporáneo" $y$ explica en qué consiste su originalidad: "La artista pretende apartar el pensamiento del hecho inferido, designado por la doctrina, para llevarlo a lo inmediato estético y to que ella demuestra es que el espectador encuentra una belleza inefable, un cuadro que calma el espíritu porque no hay en él ningún pensamiento, sino sólo el hecho puro". Solamente en los paisajes chinos clásicos ha visto también el doctor Northrop esta reproducción pictórica del hecho puro. El mejor ejemplo contemporáneo del arte en su segunda función, como el uso de lo inmediato estético transmitiendo una doctrina, que podemos llamar el arte impuro, parece que lo encuentra el doctor Northrop en los pintores muralistas contemporáneos de México "... que son pintores clásicos de la vieja escuela porque emplean los materiales estéticos para transmitir sus doctrinas... Los grandes pintores mexicanos, que, a mi juicio no tienen parangón entre los del mundo occidental, si se exceptían los más grandes como Miguel Angel, pertenecen a la tradición clásica. Creo que es necesario ir a Roma para encontrar frescos que puedan compararse con los de la trinidad mexicana formada por Rivera, Orozco y Siqueiros, y opino que incluso en Roma no se hallara, ni siquiera en la gran tradición clásica, un arte que posea la fuerza, el empuje y la pasión del arte mexicano".

Arte puro y arte impuro tenemos, pues, en la balanza, y ésta debe inclinarse segín el doctor Northrop por el primero porque "... es el que necesitamos para la paz de nuestro mundo y la ecuanimidad de nuestras propias almas, porque el arte oriental y este arte de lo inmediato estético suaviza las diferencias. Ahora bien, si algo necesita el mundo en los momentos actuales desde el punto de vista político, individual y personal, es un amortiguamiento de las convicciones de los hombres y de las naciones..." con lo cual el arte impuro como he llamado al arte en su segunda función; el arte clásico de occidente, queda descartado como innecesario en la circunstancia histórica de nuestro tiempo.

La conclusión a que ha llegado el doctor Northrop encaja, sin duda, en su propia doctrina de paz y entendimiento mundial, pero no cabe duda también de que es del todo problemática y es necesario hacer muchas reservas. La discusión del arte puro y del arte impuro está hoy día sobre la mesa y es oportuna. México ha puesto de relieve con su pintura mural que la gran tradición clásica de occidente era suceptible de ser renovada, $y$ ha producido un arte original en sus formas $y$ contenidos, renovando aquella tradición al reinstaurarla bajo nuevos signos. El resto del mundo (salvo Rusia que parece necesitar de un arte clásico realista anticuado, ese sí), en términos generales, y salvo excepciones de primera categoría como Picasso, está en favor del llamado arte puro, que es el que, según el doctor Northrop, ". . . necesitamos . . para recordarnos que estamos formados por material estético, a la vez que por ideas." 
Ahora bien, el arte impuro de México no ha esquivado ningún problema estético, sino por el contrario ha creado formas estéticas nuevas, pero a su vez, no ha esquivado ninguno de los problemas espirituales de nuestro tiempo, significados en las ideas; por lo tanto, a mi parecer, ha dado expresión artistica plena a aquello de que estamos formados, a saber: material estético e ideas, y aún más, conviene recordar, de tiempo, de historia; por eso es afortunadamente impuro y en eso y en su originalidad y monumentalidad radica su grandeza. El llamado arte puro, esquivando enfrentarse con la realidad ontológica e histórica plenamente, pretende, idealmente, expresar tan sólo nuestra parte emocional y por lo tanto es un arte muy limitado y nada grandioso.

La doctrina del doctor Northrop parece la última preconizante de liart pour lart correspondiente a msestro tiempo y usada por él filosóficamnte como instrumento adecuado para amortiguar diferencias de pueblos y naciones, es decir, en un sentido político. El arte impuro le ha hecho frente hasta a la politica. El arte puro al pretender desligarse de casi toda la vida, la historia, puesto que sólo queda ligado a ella por las emociones, no puede evitar de servir de instrumento político, así sea con las mejores y mas altas intenciones, como son las del doctor Northrop, cumpliéndose a fin de cuentas la tradición clásica de occidente en un forma a otra.

Cabe preguntarse también, si es deseable el amortiguamiento de las diferencias de los pueblos o de las naciones para que se dé el caso de un entendimiento mundial, y si éste sería auténtico sobre esa base; porque lo deseable y lo auténtico, es un entendimiento mundial capaz de comprender y aceptar las diferencias de modo de ser de los pueblos, sin las cuales el empobrecimiento de la vida, de la historia, sería definitivo... aunque gracias a Dios, imposible, y la libertad sería un mito. Para comprendernos hemos de comprender primero la realidad con plenitud.

J. F.

ARTEMIO DEL VALLE-ARIZPE:
Calle Vieja y Calle Nueva. Editorial JUS.
México, 1949.

Poco tiemo antes de que don Artemio del Valle-Arizpe, cronista de la Ciudad de México, diese a la tortura de las prensas el manuscrito de su libro La Güera Rodrigmez, que resultó sensacional, habia aparecido otro grueso volumen, obra suya también titutlada Calle vieja y calle nueva. Este relato histórico se refiere a la calle que tiene categoría de avenida. Desde su comienzo, en la esquina de El Centro Mercantil, y aún antes, desde la acequia que pasaba frente al Palacio Municipal, hoy día el edificio principal del Departamento Central, hasta su terminación, en la esquina en que se encuentra la cantina "Los Tranvías", y aún más, hasta la averida Independencia, el cronista se ha paseado y deterido en los sitios notables y característicos para contarnos mil $\mathrm{y}$ un sucedidos, para liamarnos la atención sobre algumos bellos edíficios y otros que sólo son interesantes por su historia.

Aprovecha la historia minúscula de estos sitios el cronista, para hablar de nuestra historia en sentido mís general, cuando viene al caso, y es que los minúsculos 
acontecimientos que van imprimiendo carácter a la ciudad día a día, corresponden, claro está, a una historia más amplia, la cual se enriquece con el conocimiento detallado de tanto detalle, hasta casi volver a perder sus líneas directrices.

Desde el origen de la capital de Nueva España, sobre las ruinas de la destruida Tenochtitlán, pasando por inciderites, sucesos notables y otros menos notables, hasta nuestros días, prácticamente don Artemio de Valle-Arizpe, con su buen humor tan suyo, nos cuenta la historia de la calle que eligió para revivir la vida qué ha tenido en tan largo lapso. Salpicada, si no es que empapada de anécdotas, su crónica nos deja informados de muchos hechos $y$ recuerdos olvidados o desconocidos. $Y$ junto a los sitios, edificios, portales, calles y callejones vuelven a desfilar nombres de establecimientos famosos en su tiempo: cafés, restaurantes, bancos, peluquerias, torterias, baños, teatros, colegios, conventos, palacios, cantinas y casa de diligencias, para terminar en los vecinos notables que en una $u$ otra época habitaron por ese rumbo de la ciudad. La historia del alumbrado, la del pavimento y otras, surgen entre anécdotas, sucedidos y leyendas; toda la vida, pues, de la Capital en casi cuatro siglos y medio de existencia.

El "recorrido ideal por una calle real" hecho por el cronista, utilizando cuanto pudo averiguar en libros $y$ papeles viejos, y en el almacén de los propios y ajenos recuerdos tiene positivo interés, y las setecientas páginas del volumen instruyen a la vez que deleitan, según el viejo ideal didáctico. Las ilustraciones que acompafían af texto, planos, litografías y fotografías muestran objetivamente los cambios que ha tenido la hoy Avenida del 16 de septiembre $y$ lo que aún conserva de tiempos que no han de volver. Esta crónica fragmentaria de la Ciudad de México contribuye, sin duda, al conocimiento de su historia y reserva sorpresas agradables y evocaciones al lector que pasee por aquella ruidosa avenida al lado del cronista, quién prueba con esta obra suya que cumple con su honrosa misión.

J. F.

HAROLD E. WETHEY : Colonial Architecture and Sculpture in Peru. Harvard University Press. Cambridge, Mass. 1949.

El doctor Harold E. Wethey, conocido investigador norteamericano, con la ayuda de la Fundación Rockefeller, pudo hacer un amplio estudio sobre el arte colonial en Perú y Bolivia durante los años de 1944 y 1945. El presente volumen es el fruto de esos trabajos, con la salvedad de haber dejado a un lado los monumentos de Bolivia obligado por la gran extensión que la materia presentaba.

La intención del autor, magníficamente llevada a cabo, es la de estudiar sistemáticamente el desarrollo de la arquitectura colonial que va desđe el siglo xvr, "época de conquista, colonización y conversión", hasta los albores del siglo xIx, en que Matías Maestro, con la misma fiebre de Mantiel Tolsá, se dió a destruir las obras del período inmediato anterior imponiendo el gusto por el neoclásico. Este nuevo estilo debía contemplar la independncia de cada uno de los trozos geográficos que surgieron en nuestra América. El neoclásico fué fruto tardio y remate de la cultura de los coloniales; de aquí en adelante se habia de imponer el caos estilístico durante todo el siglo xIx. 
El doctor Wethey hace también el estudio de las obras escultóricas que tienen mayor inportancia. Al referirse a las sillerías de los coros, afirma el autor que "nin. gún otro país de Sur-América posee algo comparable ni en calidad ni en cantidad"; analiza y penetra las técnicas y expresiones plásticas de los púlpitos, generalmente trabajos con incrustaciones; finalmente, son los retablos y algunas de las esculturas de imágenes las que ocupan su atención. Por otra parte la pintura y las artes menores, como el mismo autor lo aclara, quedan por ser estudiadas; esperamos que Cossio del Pomar, que recientenente acaba de publicar el Arte del Perui Pre-Colombino, llene estas lagunas en su obra en preparación: Arte del Perí Colonial.

El primero de los capítulos de la presente obra se refiere a la evolución del arte colonial en el Perú, y tiene como finalidad dar una visión panorámica de los estilos coloniales refiriéndose, en abstracto, a la arquitectura y escultura. Después de esta introducción general, que informa del contenido de los capítulos subsecuentes, encontramos dos grandes divisiones: arquitectura y escultura.

En la primera gran división, el autor hace el análisis y explicación de las técnicas y materiales de construcción, usados en el siglo Xvi en ciudades como Ayacucho y algunas otras de la región del Lago Títicaca. Los monumentos en Cuzco pertenecientes al xvir y los de Lima del xvir y xurr son ampliamente tratados, poniendo en seguida especial atención a las obras de Ayacucho y Huancavelica, situadas en la parte central del Perú. De las ciudades situadas al norte, estudia particularmente la de Cajamarca, además de Trujillo, Guadalupe, Saña y Chiclayo. En la parte sur dirige sus miradas hacia Arequipa, ciudad donde probablemente se erigió el llamado "estilo mestizo", la Provincia de Puno, y nuevamente la región del Lago Titicaca.

En la parte relativa a escultura, señala entre las sillerías de coro, las de la Catedral de Sucre, "únicas en Sur América"; las de Santo Domingo y San Agustín de Lima; las de las catedrales de Lima y Cuzco, y las de San Francisco y La Merced en esta última ciudad. Entre los púlpitos tenemos los de Santa Teresa, San Blas y la Catedral de Cuzco; en Trujillo los de Santa Clara, verdaderas maravillas del arte escultórico. De los altares mayores y retablos creemos más importantes de mencionar: el de La Trinidad en la Catedral de Cuzco y en la misma ciudad el altar mayor de San Blas y el retablo de la Soledad del templo de la Merced; en Lima el altar mayor del Templo de Jesús María. De las obras de los imagineros, La Almudena, por Juaj Tomás, y un Crứcifijo, de Martínez Montañez, entre otros, nos han llamado mucho la atención. $\$$

Completando el texto, del cual hemos entresacado algunos nombres importantes, se encuentra un verdadero archivo de fotografías que ilustran los finos análisis del doctor Wethey, con su índice respectivo; un apéndice completo de los monumentos coloniales en la ciudad de Lima; una bibliografía bastante completa sobre el Perú colonial y notas de cada uno de los capitulos, además del índice general del texto.

El único arte que puede rivalizar con el del Perú colonial, nos dice el doctor Wethey, es el de la Nueva España; Perú "nunca vió construcciones", durante el siglo xvi, como aquellas que se estaban edificando en el territorio conquistado por Hernán Cortés, pues mientras aquí se desmontaba el Gran Teocalli y sobre sus cimientos se empezaban a levantar la primitiva Catedral de México de planta basilical con tres naves, la antigua Catedral de Lima se hacía con paredes de adobe y techo de madera teniendo como planta de basilical de una sola nave angosta $y$ alargada. 
Sin embargo, en ambos países hay características que los hacen seguir una dirección paralela : los estilos gótico-isabelino, mudéjar y vislumbres del renacentista eran usados con los materiales respectivos tomados de la superficie de la tierra, y mientras Alonso García Bravo hacia la traza de la ciudad de México, Diego de Torres se convierte en urbanista de Lima y Cuzco.

Los mismos estilos, con una diferente concepción plástica se desarrollaron en ambos territorios coloniales; en la Nueva España encontramos una más ó menos declinación del arco de medio punto, que se siguió usando en el Perú debido a la tesistencia que éste presentaba a los fuertes temblores; el Herreriano se desarrolla, probablemente, más en el Perú debido a la austeridad arquitectónica que se buscó desde la época de la colonización; en México, por otra parte, hay un mayor auge del Plateresco. El barroco se desarrolló igualmente en los dos países, pero en su expresión plástica siguen caminos diferentes en aquellas obras en las que colaboran los indios, o sea, en aquellos ejemplos que no eran puramente españoles; en México surge el gran movimiento del churrigueresco mientras en Perú se prefiere el movimiento estilizado del rococó. Aparece en ambos países finalmente, la línea y la proporción del neoclásico, con una gran parte de la historia del arte sobre sus espaldas.

Parece ser que la diferencia más marcada en los edificios neocoloniales de la América Latina se debe a la cooperación del indio que, una vez conquistado, tenía que convivir con los españoles; su ayuda artística se nos antoja esencial para imprimir una nueva personalidad a las estructuras de orígen europeo, personalidad que proviene del concepto del mundo y de la vida a través de estos hombres de color moreno, ojos y cabellos negros; quién iba a decir que los descendientes de los hombres rubios, en mezcla con los de tez oscura, le iban a dar la espalda a la "Madre Espaja" un buen día y cuando esto sucedió se cierra momentáneamente el album de la Colonia.

Azberto Amador. 